\title{
A conversation with Jesse Roth, Ron Kahn, and Jeff Flier
}

W

shift our format this month to bring you three giants in medicine, Dr. Jesse Roth of the Feinstein Institutes for Medical Research, Dr. C. Ronald Kahn of the Joslin Diabetes Center at Harvard Medical School, and Dr. Jeffrey Flier of Harvard Medical School, as part of the JCI's salute to the 100th anniversary of the discovery of insulin. Roth, Kahn, and Flier (Figure 1) all played instrumental roles in the discovery and description of the insulin receptor and in elucidating the critical role it plays in diabetes. See the JCI website (https://www.jci.org/videos/ cgms) for the full interview with their full anecdotes and to get a glimpse of their extraordinary camaraderie.

JCI: Jesse, can you set the stage for us with what the scientific world thought about metabolic signaling and membrane-bound receptors in the 60s?

Roth: The story starts on July 1st, 1963, when I showed up at the NIH. I had spent the previous two years in New York with Rosalyn Yalow and Solomon Berson, working on growth hormone. I was challenged to move on to something else, so my friend Ira Pastan and I decided to develop a method to measure the first step by which hormones like insulin interact with cells to bring about their actions. In fact, in those days, most people thought that insulin immediately went into the cells, found enzymes that it could bind to, and became coenzymes.

We started to label insulin with radioactive iodine, but initial efforts didn't work well. It would bind to too many things, so we had to develop a way to make insulin that was very gently labeled so it would retain biological activity. We labeled only a small fraction of the insulin, and instead of breaking up tissues, if you worked with whole cells, that worked well. In fact, if you started out with the popular insulin-sensitive tissues, like fat or muscle or liver, it didn't work so well. But if you went to blood

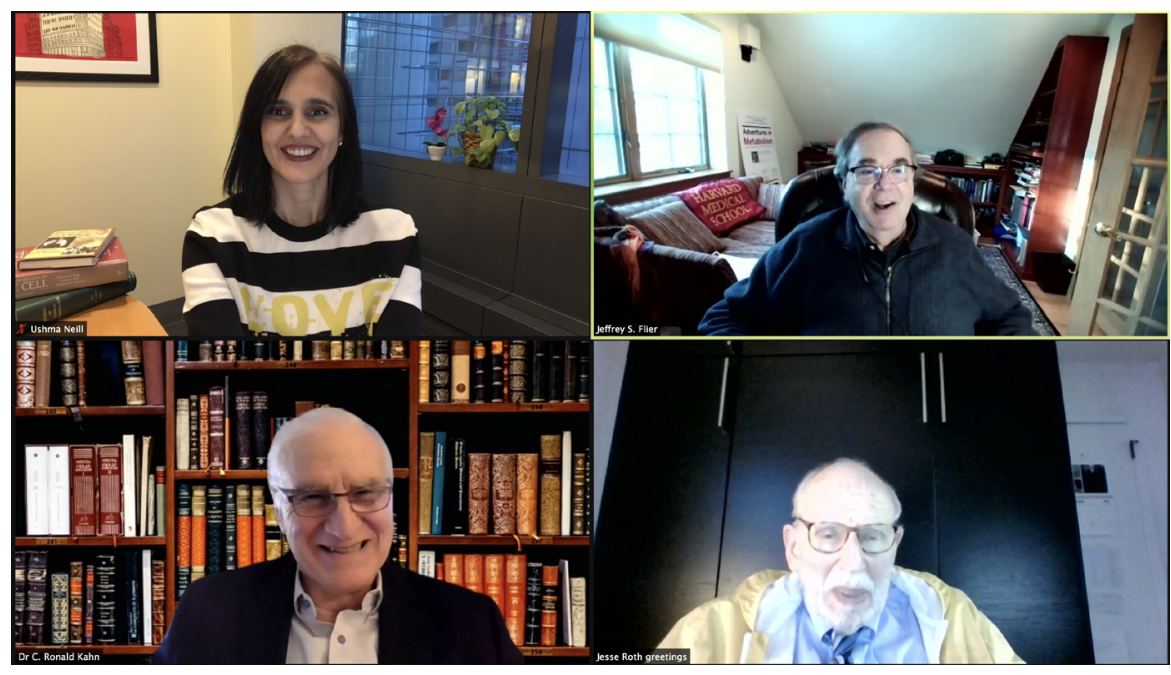

Figure 1. Ushma Neill, Jeffrey Flier, Jesse Roth, and C. Ronald Kahn (clockwise from upper left) on February 25, 2021.

cells, oh that was good. Nobody expected insulin receptors to be on the blood cells, but they were, and these were perfectly good receptors. We started to label receptors on cells from patients, and in fact, they seemed to reflect well what we thought might be the pathology of the disease.

JCI: Ron, when you arrived in Jesse's lab at the NIH, you spent about a year working on something that didn't work so well.

Kahn: My predecessor in Jesse's lab was Bob Lefkowitz, whose name is well known as a Nobel laureate for his important work on $\beta$ adrenergic receptors. Before I got to the NIH, he had been a fellow in Jesse's lab doing pioneering work on ACTH receptors. I picked up his project, but could never quite get the experiments to work as well, since the cells had changed, and one of the critical reagents was no longer available. However, I was very fortunate that at the same time, Pierre Freychet was in Jesse's lab working on the insulin receptor. So I jumped in and started to work with Jesse and Pierre on the insulin receptor, and unlike my work on ACTH, it was a very robust system and quite easily quantifiable. Because of that, we could really do the kinds of studies needed, not just to characterize the receptor, but to begin to investigate pathophysiologic states, looking for changes in diseases in which receptors might have reduced binding or increased binding.

JCI: Jeff, can you tell us about the trajectory that led you to joining Jesse's lab at the NIH?

Flier: I was in the first class at Mount Sinai Medical School. Two things that I really enjoyed: discussions of diabetes and insulin with Solomon Berson, who was the chair of medicine and Jesse's aforementioned mentor. We also had Panayotis Katsoyannis as the chair of Biochemistry, whose lab first synthesized the insulin molecule. At the same time, I got interested in cellular immunology.

I applied to 12 immunology labs at NIH and maybe two endocrine labs. I met with Professor Berson for some advice, telling him I was interested in immunology and also in insulin and diabetes. He stopped me right there and said, "There is only one lab that you should go to - Jesse Roth. He is going to transform the understanding of how signaling molecules influence cells, 
and whether you're interested ultimately in immunology or endocrinology, you must work with Jesse. I am going to call him up after you leave the office and everything will be fine." And that's exactly how it happened.

JCI: What was your project when you first started in the lab?

Flier: I had never done research on insulin, and when I got there, it was an awe-inspiring environment: Jesse was the tower of power, and Ron was the rising star - a guy coming out of his training who was leading a number of important projects. Jesse gave me complete freedom, and what ended up happening was that I tried and failed at about five projects. I was beginning to think about leaving to go back to clinical work.

We used to have Friday afternoon clinical rounds, and at one of these, a patient with severe insulin resistance was presented. The fellow presenting the case said that the patient had very little insulin binding to their blood cells. While people were asking questions, I became fascinated by several autoimmune features in the patient's history. I was about to raise my hand and ask, "What about an autoimmune basis for the insulin resistance caused by antibodies attacking the receptors?" But I waited and asked a few people questions over the next week or two and found no evidence that anyone had been considering that explanation.

At a certain point, I went to Jesse and I said, "My work hasn't been going anywhere, I have this idea, and I'd like to test the possibility that some of these patients had autoantibodies against their insulin receptors." Jesse gave me the opportunity to pull together some sera and cells and do the experiments. The initial results were clearly positive, and then it took several months to prove that the inhibitory molecules were truly autoantibodies.

JCI: How much were you three involved in treating patients with severe insulin resistance?

Roth: We actually went out to look for them! Within a relatively short time, we got six patients who had extreme insulin resistance. Three of the patients turned out to have antibodies to insulin receptor; another three were ultimately shown to have inborn errors of the insulin receptor gene that prevented its expression or action. What was a miracle is that we did not initially distinguish between these two groups of patients, but once you saw the two groups of patients, how idiotic was it that we missed it? The excitement of these findings is, I think even now, $N$ years later, still reminding us of how we kind of stumbled into these exciting findings.

Flier: I have always said I was unbelievably fortunate to get myself in a position where I could have an idea and conduct an experiment that worked and was meaningful. The good fortune came from the fact that Jesse had established this field from nothing and became an advocate and a leader. He and Ron and the larger team were characterizing these molecules as biochemical entities that you could study kinetically for how they interacted with insulin and ultimately related to the biology of the hormone.

I had the good fortune of having the idea about autoantibodies, then characterizing what they actually were, after which it became possible to use the antibodies as powerful analytic tools. If you talk to scientists training in molecular science today, everybody just orders antibodies; but at that time, there were no well-defined antireceptor antibodies in existence. Some of these patients had extraordinarily high antibody titers that enabled an almost infinite number of experiments to characterize the receptors in ways that Ron and I and many others began to do. None better than Ron.

Kahn: In this era before molecular biology, these patient-derived antibodies really became the tool to understand the receptor. The receptor hadn't been purified, it hadn't been cloned, and nobody knew anything about it. But using the patient-derived antibodies, we were able to do biosynthetic labeling, determine the receptor structure, and demonstrate that there was a proreceptor that was cleaved to give the two receptor subunits. We were even able to figure out their basic stoichiometry. We were also able to use these same receptor antibodies to do immunoprecipitation to show that the receptor was a tyrosine kinase that underwent autophosphorylation. Ultimately, when the receptor was cloned in 1985, we already knew that the receptor was from a single-chain precursor, existed as a tetramer with $\alpha$ and $\beta$ subunits, and was a tyrosine kinase. The cloning simply confirmed all of these things.

JCI: When you started this out, as Jesse has noted, many thought that there wasn't a receptor for insulin. So what was the reaction to your findings? Were you lauded? Were you laughed at?

Kahn: For sure, there was pushback on the idea of receptors being regulated. People had thought that there must be receptors of some kind, although, as Jesse pointed out, there was also this notion that insulin might enter the cell and directly interact with target proteins through its disulfide bonds. But there were certainly plenty of other suggestions that there were surface receptors for other molecules that could be present; that part was not so hard to get accepted. But what was hard to get accepted was the idea that these receptors might be regulated physiologically and in disease. Everybody assumed that hormones go up, hormones go down. And as a result, signaling goes up, signaling goes down. What became very clear is that the receptor is an equal partner in signaling, and the receptor too can go up or the receptor can go down or it can change its affinity and change its biologic effects.

A bigger debate, even in the Diabetes Branch, came, however, when Jesse proposed that it was insulin itself that was regulating the receptor. Pretty soon, however, people realized that this was true and that this wasn't unique to insulin. Soon NIH became a remarkable hotbed of science and signaling. Peptide hormone signaling in particular was part of the hottest part of that hotbed, especially during the period from 1968 to 1969 through to about 1980.

Flier: A dominant question at the time was whether disorders of the receptor really play a role in disease. And exactly how does insulin binding to the receptor cause anything to happen within the cell? During the four years I was there, it wasn't yet possible to say how insulin binding to the receptor caused the activity of enzymes and transport to change. That required the discovery a few years later of insulin-stimulated receptor autophosphorylation and the tyrosine kinase activity of the receptor. And as far as the receptor being critical for disease - it really was these extreme insulin-resistant patients that were the key. The antireceptor autoantibodies were really the initial proof that antibodies 
blocking the receptor caused a patient to have tremendously severe insulin-resistant diabetes. Once that was shown, there couldn't be any further pushback to the idea that the insulin receptor was a necessary component of insulin action.

I'd like to ask a question of Jesse and Ron that reflects my own opinion: today, we still can't answer the question of why patients develop insulin resistance and type 2 diabetes - even with all the tools, genetics, biochemical reagents, and longitudinal studies that we have used to study this. In 2021, we have a lot of facts, innumerable interesting insights, but we don't yet have the answer to the fundamental question: what are the primary and sufficient causes of cellular insulin resistance in typical type 2 diabetes and related diseases?

Roth: Jeffrey, I think that you're right, and it's interesting too, because every few months somebody comes out with a paper claiming to have found it, and I read the paper quickly and shake my head, and I say, "Nope, that didn't do it." I read the articles with excitement, but with continuing skepticism that they have found the answer.

Kahn: I think it's fair to say that Jeff is right in saying that we don't really know the absolute cause of insulin resistance in type 2 diabetes. We've made a lot of progress trying to dissect the various mechanisms of disease, and there's beautiful work that's been done by many labs looking at external drivers of insulin resistance, such as inflammation, fatty acids, branched chain amino acids, and other factors which are dysregulated and can drive the cell to become insulin resistant.

Our recent work has focused on the fact that, using iPS cells from humans with type 2 diabetes made into muscle in vitro, we can show that there is also a cell-autonomous defect, that is, something in the cell itself that's already resistant even before you add all these extrinsic factors. This is to me the real question, whether it's extrin- sic or intrinsic. What is the driver? This is the real challenge, not just for diabetes, but most of the most common polygenic diseases. Genetics has been instructive and identified many loci that are linked statistically to these diseases, but only in a very small fraction of times is it known how those genetic loci actually create a pathophysiologic mechanism. In my lab, we are beginning to think beyond genomewide association studies, that is, beyond one gene or even one group of genes, to the $3 \mathrm{D}$ organization of nuclear chromatin and regulatory factors that change gene expression.

Flier: There has been massive progress, but I think you would agree, Ron, that you would have thought 20 to 30 years ago that we would be closer to having nailed down the molecular explanations for insulin resistance than we appear to be today.

Kahn: I agree.

Ushma S. Neill 